\title{
Information and wisdom in the practice of knowledge
}

\author{
Satoru Nakagawa, University of Alberta \\ nakagawa@ualberta.ca
}

\begin{abstract}
Extending current theories, this paper merges binarized western and Indigenous ideologies into a fused "one world" view by addressing how two knowledge systems - namely wisdom-based knowledge (WBK) and information-based knowledge (IBK) articulate together. I suggest that current educational systems worldwide are based on IBK, which is replacing and/or annexing the WBK of Indigenous societies. I argue that if WBK is the first imprint on children, then WBK will form their ideological foundation. Noting that those of us who have higher education are recognized by the dominant society and within our own societies as authorities, I suggest that those of us with higher degrees need to change our positions from "information providers and brokers" to "warriors of the truth" (Alfred, 2004, p. 95) against the hegemony of dominant cultures.
\end{abstract}

\section{Introduction}

To this date, researchers from non-dominant spaces around the world have attempted to decolonize and/or re/claim their self-determined traditional beings from colonization, modern capitalism and/or other theories of world order. There are many perspectives from which scholars write such as the relation of personal experiences (wa Thiong'o, 1986), critique of western research and the proposal of Indigenous research tools (Smith, 1999), deconstructing and reviewing history from an Indigenous perspective (Stewart-Harawira, 2005), belief in autonomy and the championing of "Warrior Scholarship" (Alfred, 2004), the "regrounding" of "Red pedagogy" which "compels students to question how (whitestream) knowledge is related to the processes of colonization" from a critical, decolonizing stance (Grande, 2004, p. 56), and several other perspectives which, on some level, recognize/reify a dichotomy between what is basically reduced to western scientific and Indigenous worldviews. Some have tried to resolve this binary by suggesting that there is a third or merging space, a "cultural

Journal of Contemporary Issues in Education, 2008, 3(2), pp. 24-45.

ISSN 1718-4770 C 2008 University of Alberta

http://ejournals.library.ualberta.ca/index.php/JCIE 
interface" in the words of Nakata (2002) where "traditional forms and ways of knowing, or the residue of those, that we bring from the pre-contact historical trajectory inform how we think and act and so do Western ways" (p. 7), a kind of "ethical space" between western and Indigenous worlds, disrupting both (Ermine, 2006), or a "third space" existing outside of western and Indigenous worlds (Bhabha, 1994) which can be extended and explored. This paper will extend these arguments, theories, and philosophies which situate two binarized worldviews, merging them into a fused "one world" absolute reality by addressing how knowledges articulate together. To do so, in keeping with both my argument and my ethical beliefs, I will begin with personal positionality.

My name is Satoru Nakagawa. I am from an island called Tokunoshima. Someone might immediately say to me, even in Japan, "where is Tokunoshima?"1 I always wonder what I should say to make this person understand the exact location of my island. Which reference point is the best reference point to start from? Then I have to ask myself, "how much does this person know, or want to know, about me?" That is, I try to determine how much information we share in terms of both background knowledge and intimacy.

Tokunoshima is one of the southern islands of Japan. The island is very close to Okinawa. Therefore, normally I will answer the question with, "I am from Japan," which is followed by my question "Do you know about Okinawa, where the United States military base is located?" I need to know how much the people who are asking me questions know about Japan, especially the southern region of Japan. Most of the time, I need to start with the assumption that people do not understand or know anything about the regions of southern Japan. If this tactic of using Okinawa as reference point does not work, then I will use Taiwan as the next reference point to locate my island. In all of these cases, I am really assuming that people understand where Japan is, where Taiwan is, and possibly then where Okinawa is - between them. My reference choices are based on the fundamental assumption that most people understand and know the divisions between countries around the world, and that they know something about the border lines that

\footnotetext{
${ }^{1}$ As an interesting example, on Friday, March $29^{\text {th }}, 2007$, a Japanese military helicopter summoned to evacuate an acute medical emergency crashed into the side of Amagi Mountain in Tokunoshima, killing four military personnel on board. Initially news reports said Tokunoshima was located in Okinawa Prefecture, not in Kagoshima Prefecture. When the prefecture was identified properly, Tokunoshima was referred to as "remote", being "200 kilometers northeast of Naha" (the capital of Okinawa), so that Japanese people would know where it was.
} 
surround countries.

However, there are many other ways to explain where Tokunoshima is located. The island of Tokunoshima is located at approximately north 27.5 degrees and east 129 degrees with reference to Greenwich, England, a location I can describe when people understand the system of longitude and latitude as represented on a globe (i.e., earth). Or I can locate my island from Edmonton, Canada, followed by directions such as you have to go toward the west and south; or it is about 15 hours ahead of our time; or I can speak of the number of airplane rides and the approximate flight length (specifically three airplane rides of two hours, eleven hours and three hours respectively, followed by seven hours overnight in Naha, and nine hours on a ferry); or simply "on the other side of the Pacific Ocean" may good enough for some people. For some knowledgeable people, I can simply use the address system of Japan: Yubin bango (postal code) 891-7710, Kagoshima-ken, Ooshima-gun, Tokunoshima-cho, Kametsu, 7701.

Whichever system I try to use to describe the location of my island, I end up using units which are legitimated by the dominant society/culture, whether I am locating it either here in Canada, or in Japan. On the other hand, there are no ways to express the location of my island using my own language without reference to the outside world. Does this mean my island is primitive and globally marginalized? Actually, I wonder why we, as Tokunoshima people, ever have to describe ourselves to the outside world from within our world. Are we invading the outside world (likely impossible), or is the outside world invading us and causing us to be like them? As we are being invaded, need we locate ourselves to the invaders?

After briefly expressing many ways of explaining where Tokunoshima is, using all of these methods that locate the island where I was born and grew up, I am forced to realize that I am only capable of providing this knowledge using world standardized units: countries, borders, latitude and longitude lines, divisions of the earth, hemispheres, directions, distances, times, and names of Oceans. I am sure there are many other ways to express the location of Tokunoshima to outsiders, but I do not know how my people used to do so. I am not even sure we should be traveling around the world just because I can or I want to, and maybe I should not describe where my island is at all because that may lead to us being "discovered" by linguists! ${ }^{2}$. We may have to travel without the power of technology and science, rediscovering how to navigate by the stars as my ancestors did. Maybe that would allow me to explain where I am from using my standard and my units. Maybe that would help me to find my reference point in my own culture and language, or

\footnotetext{
${ }^{2}$ I owe thanks for this idea to Dr. Makere Stewart-Harawira (personal communication, March, 2007).
} 
at least to define where we would like to be located as a group of people.

I cannot think of any geographical units that are used by my people. Anyone can argue Tokunoshima people do not have their own intelligence(s) to reproduce geographical units like those units of measure used in dominant English-speaking societies, countries and/or nations such as the United States, England, Australia, New Zealand, or Canada, or that adopted as the international standard, the French-based metric unit. Why I am forced to use international units without asking questions? And, why am I only able to use international units to explain where I am from?

These questions lead me to question why I need to explain who I am within units that I did not grow up with, or even units that represent my own worldview. At this moment, living in Canada, I can only say that I have left my island, and, as a consequence, I must use someone else's units to describe and explain who I am. But I have to use these units to describe who and where and what I am, even in Japan. In addition, these units seem to be set by specific groups of people who have the power to do so, people who have made it necessary for me to locate myself, as if locating myself in international units gives me legitimacy. This is, in essence, another manifestation of internalized racism (Dei, 1996, p. 49).

Despite the fact that international metric units invaded my island, my culture, and my Japanese language (but not my Tokunoshima language which has its own measurements for weight and island distances), I feel at home when I go back to my island. My town has been changing rapidly since World War II, especially after the 1960s, since which time the Tokunoshima/Amami island movement for better education and living standards has been advocating for equity in Japanese governmental practices. Our houses changed from thatched roofs to tin roofs to having steel reinforced concrete buildings, including residences like my own parents' house in the middle of town, built on "reclaimed" ground, which was not really reclaimed at all but rather made by filling in the coral reef. The construction of many such modern houses may be seen as resistance to the repeated visits from typhoons, a yearly event. Or, it may be that the modernized look of the housing is a symbol which shows off our newly accumulated wealth. ${ }^{3}$ Whatever the reason, we almost no longer use our own housing, or any of the other units of our traditional lives. When I see the materialistic aspects of modernization, even I view my island peoples as having a better life than ever before; the island now has better breakwaters, steel bridges, paved roads, community centers, recreational fields, and so on.

${ }^{3}$ It should be noted, however, that Tokunoshima is not wealthy in comparison to Japan. Tokunoshima is considered poor and rural by modern Japanese standards. 
Children are more integrated with the "international community" through the computer, and they are familiar with the urban lifestyle. They act differently and speak a different language from the older generations.

My mother once said to me that "the beauty about this island is that if you do not ask much from life, the island will give you everything you need." I am not sure that this is true any more. That is, it is true that if you do not ask for much, the island will provide everything you need, but the basic needs of islanders have changed. What islanders want has become what islanders need. Consequently, the three basic needs of housing, clothing, and food which sustain life are now supplied from outside the island. Especially members of the younger generation are living in a new era, seeing Tokunoshima as a dependant appendage of "mainstream" Japan. As I describe these facts of island life, I see these changes as representing how the ontology of the island is changing. I do not want to see these changes, but I see the island mind, the island worldview, the island ways shifting; our epistemology is then forced to shift according to the life styles we adopt. The way we now live on the island is becoming our epistemology. Tokunoshima peoples' material lives started to improve when they adapted to the dominant Japanese culture, and as they became seduced by the capitalist way of life. The local island people start to import advanced technologies, medicine, materials, and even vital food sources. The island people "bought into" everything the dominant culture had to offer, even when it did not make sense.

Why have I told this story? I want to illustrate that the standardized Japanese education system is working well, and that people on the island are working hard to fit themselves, or rather their hearts, into the prescribed box of the mainland Japanese culture and economy (Tai, 2003). With the establishment of the modern Japanese government in 1867, Japan started a new curriculum to teach standardized Japanese and other subject areas in 1872 (Hozumi, 1995). The curriculum was, and still is, intended to form a national identity for Japan by standardizing language and cultural concepts (Tai, 2003), that is, the purpose of Japanese compulsory education was "to patrol the boundaries of social and linguistic conformity upon which the state depended for its continuity"(Maher, 2001, p. vii). The Japanese education system on the island, like a heat-seeking missile, is burrowing into, and even replacing, traditional island lifestyles; moreover, it is technically illegal for islanders to establish alternative education forms because Article 26 of the Japanese constitution as established by the American General MacArthur at the end of World War II makes it legally compulsory for children to attend accredited schools, effectively shutting out other systems. The education system is not accountable for the consequences of peoples ingesting its prescribed knowledge; 
therefore, people on the island are unknowingly (but willingly) trying to fit themselves into a box which has a much different shape than their own box. The people on the island are well educated nowadays; we almost cannot see our own unique shape, our own physical and mental attire.

As just one example, the educational curriculum in Japan is national. Children take classes in morals, ethics, and home economics along with science, languages, and math. My sister, a grade one teacher, has to teach her students a story about walking through puddles when it is freezing and when, therefore, stepping on the water makes a sound. Her students cannot comprehend this story. On Tokunoshima, the temperature never reaches zero. My sister has to carefully freeze a bucket of water to get a coat of ice on top so as to demonstrate why the water makes a crunching sound. As a result, the beauty of the story is lost in trying to demonstrate its meaning. She must use technology to demonstrate another "truth" to the students, one which is being presented as a universal truth in Japan. Why is this happening? Is it inevitable? We need to think and refine questions like "Where does this system come from?" and "How did it come into the island?"

In 1945, at the end of WWII, General MacArthur provided Japan with the Japanese national constitution, modeled on the American constitution. While most people are aware that the constitution changed the Japanese Emperor from a God into a man, they are not aware that the new constitution also included many other factors, such as economic re-establishment, a modified education system, democracy, a human rights agenda, and many other "improvements" which affected Japanese government and culture. These changes and demands constituted by America were intended to reconstruct the Japanese and their government's future. To this date, Japanese people are religiously hanging onto the constitution provided by United States. Japan is still living with the ghost of WWII, unable to maintain independent armed forces except for defensive purposes, and unwilling or unable to make independent decisions about whether or not to support American interests in the War on Terror.

With these changes in Japan, so too, come the changes in Tokunoshima. American based education and social systems have been incorporated into the islanders' daily lives, reflected in demands for equity, rights, and higher living standards. At one time in island history, such demands may have been seen as necessary for survival. But, now we have more than achieved the minimal requirements for survival, and have begun to pursue accumulation. We need to re-examine the education system that we believe has saved us, understanding where it has come from, and where it is taking us.

In an often-quoted line, Audre Lorde (1984) noted, that "the master's tools will 
never dismantle the master's house. They may allow us temporarily to beat him at his own game, but they will never enable us to bring about genuine change" (cited in Anderson, 2003, p. 321). I disagree with Lorde. We need the master's tools to dismantle the master's house; however, we cannot then use the father's tools to rebuild our own house without ending up with the same house. Perhaps we are like the Native Americans Allen (1989) refers to in another context, "We had to ask ourselves if we were traitors to our Indianness? Maybe we were so assimilated, so un-Indian, that we had been doing white folk's work and didn't realize it" (p. 4). Perhaps we are doing the dominator's work now, re-colonizing ourselves rather than decolonizing ourselves. If we ask hard questions about the past, the present, and the implications for the future, then we will know if we need to invent new tools or not.

Assuming that the accumulation of wealth is one of the conditions allowing us to wonder and think about our existence and the facts of our lives (Marx, 2005), it follows that we then need to invent and evolve our thoughts and inventions. We generally prefer to call the invention of knowledge "science" and "technology." Science and technology can be viewed as nothing more than facts-driven dominant ideas, or ideas that have been established and verified through a dominant form of logic (Ong, 1977, pp. 35-49; see also Gadamer, 2000, 9-17), often replacing ideas that were established through years of local and intimate observation of specific geographic spaces and their productive capacities over time and space (e.g., Esteva, 1996; Nadasdy, 2006). The idea behind facts-driven dominant ideas is that the accumulation of food re/sources will likely lead to being able to control those persons or groups who depend on that food to live. Eventually, the accumulation of food which comprises, at least in relative terms, one part of the equivalent of "commodity" will be replaced by a single commodity of universal equivalency (Marx, 1906), currently "money" but gold in the past. Furthermore, the accumulation of food will lead to the accumulation of knowledge, with the result being the knowledge of how to control others, as well as their ontological environments, such as their actual physical surroundings, working conditions, working tools, and daily lives.

Hereafter, this current dominant system and its knowledge will be referred to as the information based knowledge system (IBK system) in order to distinguish it from what has been variously called western knowledge, scientific knowledge (Lafrance \& Bastien, 2007), dominant knowledge (Rooney, 2005), imperial knowledge (Alfred, 2004), one local knowledge that has taken over the world (Canagarajah, 2002) or the knowledge of the oppressor (Freire, 1970). I am proposing that the term "information based knowledge" (IBK) be used in order to recognize that anyone can possess this knowledge and thereby become either oppressors/dominators/colonizers or oppressed/ 
dominated/colonized. It is important to know that this information-based knowledge system is a facts-based knowledge system, and that it is up to individuals to make decisions about how they perceive IBK, rather than to presuppose that IBK itself provides power for domination. The perceptions of individuals and the actions which follow from their perceptions of IBK are important, since IBK itself bases its values, ideologies, meanings, and/or truths on the current dominating ideological world including the worldwide exchange of currency (see Alfred, 1999, pp. 114-115). It is not the knowledge itself which is dominant, oppressive, imperial, or Western, but rather it is the use of IBK which results in dominance, oppression, colonization/imperialism, and Westernization.

Yet, I am still comfortable going back to my island. I am able to feel that I am still part of them. I can still see the spirit of the island in the people who live there. I feel connected to the island and to island' ways, a belonging that I sometimes fear will disappear when my parents pass away. But, even if that is the case, my own base knowledge, my own truth, comes from island ontology. I spent my entire childhood and puberty, what Bloom (1964) and Lenneberg (1967) refer to as the "critical" age for learning language and knowledge, on the island, breathing island ontology along with the ocean air.

In my experience, throughout my life, almost all of the people I have met have learned from the current education system-learning facts and information about, not within, their lives and their surroundings. Moreover, just like me, most people around the world have learned their life values, beliefs, meanings, truths, and understandings, through oral teachings from their parents, from birth:

Talk is a crucial link between parents and children: It is how parents impart their cultures to their children and enable them to become the kind of men and women they want them to be. When parents lose the means for socializing and influencing their children, rifts develop and families lose the intimacy that comes from shared beliefs and understandings (Wong Fillmore, 1991, p. 343).

Most of us spend our first foundation-building time (age 0 to 3-5 years) and space (home) with our parent(s)/guardian(s), until we enter into nursery/pre-school system, and we continue foundation building at home until reaching the age of puberty (Bloom, 1964; Lenneberg, 1967). Coming from a small community, I likewise learned my life values from my parents and other surrounding adults, even after entering the school system. However, teachers at school taught me facts and information, which have been very 
useful to this date. I use this knowledge differently from the knowledge I learned from my parents and community. I almost always use the information I learned through the education system to control my life and my environment. For example, I used to think "after receiving this degree or certificate, I will make more money; I will have a better job; and I will have a better life, (which I defined as a more comfortable life) and then I will allow myself to proceed further in my chosen career" (first teaching, then engineering, then kinesiology...). On the other hand, the core values I learned at home through parents, relatives, neighbors, and other community members include knowledge of loving, caring, sharing, giving, the fundamentals of being human within my own particular unit of people, area, country, nation, and/or system. This knowledge is best described as wisdom-based knowledge (WBK) and can be understood simply as "truth seeking" within the family, community, or local area. The truth seeking methods and manners of WBK are passed down by parents, relatives, neighbors, and other community members. It is important to notice in this part of the discussion that the WBK system contains most elements within the IBK system such as math, chemistry, physics, geography, biology, zoology, medicine, and many other advanced scientific or technological information. It is important to recognize that almost all fundamental factors of science and technology and many advanced concepts of science and technology are already embedded in the WBK, but are not divided into disciplines but rather approached holistically. For example, simple addition, subtraction, multiplication, division, production and/or purification of various metals, astronomy, tide and wind reading, mapping of the/a world, various concepts of various and gravity, all exist within WBK.

The point here is that WBK did have IBK systems within them, but that WBK was the controlling factor in the same way that in the current world order, IBK dominates WBK. In fact, as I have argued elsewhere, IBK is one local knowledge (Kouritzin \& Nakagawa, forthcoming)) and therefore one WBK system. But that system, having now been forced on the rest of the world, is no longer embedded knowledge, and no longer is essential to the sustaining of life in a particular region. It is one WBK run amok, one local knowledge out of control, one local knowledge that has married an economic system (capitalism) and colonization.

Around the world, WBK seems to have almost no validity within the discourses of IBK, probably because to do so would force the recognition that IBK is nothing more than one WBK wedded to capitalism and gone global. WBK is not the same as what has been termed traditional ecological knowledge, or TEK (e.g., Nadasdy, 2006), or "local indigenous knowledge" (Dei, 1996), meaning merely Indigenous experiential knowledge about local lands and ecosystems. WBK, because it is a form of truth-seeking, is not 
limited to human beings. WBK has no "arithmetic" or "foreign language study" (that is, as I noted above, it is not divided into disciplines); on the other hand, there are numerous instances of animals speaking within and across species (e.g., Gottfried, Andrews, \& Haug, 1985; Sinha, 2004; Slater, Ince, \& Colgan, 1980; Snowdon, 2004), meaning that there is no hierarchy of human knowledge and the knowledge of other species. For example, we have all seen that any animal will escape from humans or other species when those "others" approach to within a certain distance, a defense mechanism skill that can only be described as arithmetical. Of course, there must be a space for errors within the defense mechanisms of animals; otherwise, no animal would become the food enabling the survival of another. In other words, as organic creatures, we all communicate, we all calculate, and we all need each other. Humans, however, seem to think that only we can change and manipulate our environments, since we are the only one who can use language and arithmetic (IBK) to do so. We are only fooling ourselves to believe either that we can, or that we are the only beings who try.

I suggest therefore that it is impossible to dichotomize many ideas as belonging purely to IBK or WBK systems. The distinction between what constitutes IBK and WBK can be only assumed when knowledge is used, at the line/time of change and/or manipulation of our environment to benefit us and our own generation, without thought or concern for future generations. The distinction is well-articulated in the review of global warming by the former head of the World Bank (Stern, 2006) who raises questions about intra-generational and inter-generational equity in terms of the current world crisis. Stern (2006) notes that:

Climate change will have serious impacts within the lifetime of most of those alive today. Future generations will be even more strongly affected, yet they lack representation in present-day decisions. (p. 23)

WBK considers the truth of being (the way of life, ontology, epistemology, value, meaning, worldview) within a particular location and environment, enabling survival both now and for future generations. In short, WBK will provide what it takes to live together in a particular time and space as a unit of people under consensus, that is, living one truth within one community.

It is my position that we all possess both WBK, and later learn IBK. In fact, I am often torn between these distinct sets of perceived teaching/learning systems that, at the extreme end of the ideological spectrum should annex other ideologies and thereby change my reference point. It feels like my IBK system is trying to take over, cover, and 
mask my WBK system. In fact it is more like my IBK telling me that the left side of my brain is better than the right side or vice versa, but my WBK is laughing at my IBK, saying that it takes all of us to survive as a human/system. I am wondering how and whether these ideologically distinct perspectives can coexist in me, simultaneously. Why is it that these clearly different but curiously entangled systems are in competition in my mind and heart, and yet I am functioning as one ordinary person?

Looking back at my own life and how my parents lived, I soon realize that my father was the manager of sugar factory (IBK) who dreamed and eventually built a steel reinforced concrete house to live in (IBK). But, at the same time, he has been helping his family members and relatives throughout his life, physically, emotionally, and financially (WBK). He grows mangoes without chemical intervention (WBK) that have become famous throughout Japan and are therefore sold and shipped throughout the country (IBK). I assume that, in his life, he must have learned the truth of his family and community from his parents and his community. My mother practices ikebana (WBK) and runs a small ikebana school (IBK). Despite having many other siblings who could help if they were willing, my parents have looked after, and are still looking after, both of their mothers into their eternal life destinations (WBK). My parents are living within two distinctive worldviews simultaneously, and are able to make sense of their own ways. I am sure they themselves do not distinguish the differences between the two worlds, but they are not confused. I think this is possible since they were grounded in the ways of life of Tokunoshima and in their elders' teachings at their most crucial ages; what they were taught when they were very young was not contradicted until the end of puberty. I think my parents are well grounded in the WBK system, but that they are able to use IBK within the system of WBK. That is, specifically, the WBK system is the envelope system, and therefore IBK works within WBK rather than the other way around. If it were to work the other way around, then the envelope system would be IBK, and therefore the dominant system would be IBK.

It is important to note the strong generational shifts in our own perspectives on IBK (i.e., the standardized Japanese education system) as the goal, and/or basis of their lives. My parents, from whom I learned my core values, and who showed me the importance of human wisdom by showing and by acting it, are very proud that their son is pursuing a Ph.D. in an English-based university system (IBK). It is their pride, which is a mark of achievement within their community and their circle of friends. Marks of mainstream success, whether business, politics, education, or fame, are now common goals for the islanders. But, for those who are so successful (my generation), island life is no longer possible. So, the question may be raised, how are my parents able to use IBK 
within the WBK, despite having achieved a relatively high education compared to others within our society? How can I do the same? I think and hope it has to do with imprinting, because that will make it possible for me too. If we change the word "species" to "peoples", then as Lenneberg (1971) notes, "every aspect of an organism's behavior bears the indelible imprint of the biological operating principles of its own species" (p.2).

\section{Human learning behavior: How do we learn to behave?}

Japan has a saying: "children will grow up watching their parents' backs." As I understand it, the English equivalent is "the apple does not fall far from the tree." While I was growing up, my parents showed me life the way they lived, and they also showed me the way my grandmothers lived. My parents, just like anyone else's parents, showed me how to give honor and respect to elders and older persons, to serve, and to take responsibility. It was never a question to me what they were doing with their lives.

Now I have become a father of two children and I think I am acting more like my parents than ever before. Whether I like behaving like my parents or not is not a question here, but rather I have started to see their life truths from their points of view. I am now at the age my parents were when they showed me their actions rather than preaching to me. I hope that I am doing the same for my children (though it is hard from Tokunoshima to Canada). That is, I hope I am crossing the road when the light is green or at the corner of the street; I hope I am not littering rather than placing garbage in the garbage can; I know I am not cheating on my taxes, or hanging the laundry outside when it is a sunny day; I walk rather than drive; I do not kill bugs except to protect myself; I do not kill animals except to eat; I try not to hurt others or offend them; I do not judge my children's friends (though I admit I sometimes question what their parents have taught them, especially when my children are not white enough in Canada and not pure enough in Japan); I limit my gas, air, and water consumption and do many other things that I can do to reduce my personal impact on earth. I hope that in every action I reflect to my children what I expect them to do. (Of course I sometimes break my own rules).

In my everyday life, I therefore enact a universal and timeless teaching style, supporting the saying that "actions speaks louder than words," a saying, that has been interestingly well-supported by research evidence (Lenneberg, 1967; Rosenhan \& White, 1967; Rosenhan, Frederick \& Burrowes, 1968). For example, researchers found that, left alone, children will copy the behavior they have seen in adult authorities, rather than behave in ways that adult authorities have told them they should/must (Lenneberg, 1967; Rosenhan \& White 1967; Rosenhan et al., 1968). Rosenhan and his colleagues tested 
children with a game; based on their performances, children were rewarded with tokens which could be exchanged for toys at toy store (Rosenhan \& White, 1967; Rosenhan et. al., 1968). Children were shown how to play a newly invented game which they played with adult authorities; the adult authorities would either apply the rules strictly for both themselves and the children, apply the rules leniently for the children but not for themselves, or apply the rules leniently for themselves but not for the children. When the adult authorities left the room, the researchers found that those children who watched adults who had been strict with themselves did not reward themselves with tokens undeservedly, while those who were taught by the self-rewarding adult also rewarded themselves when they did not deserve it. The conclusion was clear; students who were taught the rule and whose teachers practiced the rule did not cheat, received lower scores, and therefore received a lower number of treats. But, students who learned from teachers who taught the rules but did not practice the rules did cheat, and treated themselves with more tokens than their scores indicated.

These studies can be seen to support the universal understandings of old timers, that children and learners will follow the person ahead of them, in their footsteps, rather than follow the route that person says is the best one to take. In this saying, two layers of meaning seem to be embedded. First, as illustrated above, actions speak louder than words. Second, learners have a tendency to follow the first way they learned, rather than the best way available. The second case is an imprinting effect on first time learners; for example, my friend once told me his story about his teaching method, and I recall it:

I was a high school English teacher in Japan. I am retired now. I think students used to think I was a very tough and disciplined teacher and they were not really fond of me. When I look back my teaching days, I have to agree with my ex-students. I was a very tough teacher. I taught grammar translation based English classes to the students in my English classes in Japan. But there was not much I could have done with my teaching style, since that was the way I was taught and that was the only way I knew how to teach. When I reminisce about my own teacher's teaching method, I have to say he was a very tough teacher and I must agree that he was not a good teacher. But I was good at what he taught so I pursued my career in a similar manner. I could only teach the way I have been taught at the beginning. (Kai Kondo, personal communication, July, 2004).

We learn one thing in a particular way, and then we tend to stick to the way we learned the first time, normally, the way our parents or caretakers showed us how they do 
things. Their being/ontology is imprinted onto (and into) us; therefore we often follow in the footsteps that our parents and/or caretakers walked before us. The point I am making here is that, as adult authorities, what we do rather than what we say/preach is important. It is this traditional but well-documented knowledge that I need to reflect on, both for myself and for my community, during my planning and participation in language and culture revitalization, a form of self-reclamation for islanders. On the stage during such a community leading project, the leaders must question themselves and analyze the significance of their actions, rather than merely carefully watching their words. In my case, I need to critically analyze my own life and my own intentions about what I would like to accomplish. That is, "what is it that I am going to tell people in the island communities that they need to do?" and, more importantly, I have to answer with honesty the resulting question: "what will my own actions be and what am I prepared to sacrifice?"

Fortunately, I am learning how to lead and how not to lead communities in my Ph.D. program. Yet, it seems to me that I am not learning, or even questioning, what my actions should be when I preach the doctrine of self-reclamation. I have already left the community. I can no longer speak the language with ease. I make no economic contribution to the island, and do not provide resources. I have already obtained more IBK education than any other islander in history. Even from among just these few listed self-critical points, I can see that my actions can easily defeat my talk. Moreover, if I were to start my reclaiming actions by teaching language and culture within a traditional notion of "schooling" from the comfortable position of having a $\mathrm{Ph} . \mathrm{D}$. and some title on my business card, I have to wonder if this is the picture I want to portray as a leader, or if I should be able to live life on my island within the traditional lifestyles (keeping in mind that we cannot really reproduce--or even recall--what our traditional lives were like), turning my back on my education and my Ph.D, in the attempt to achieve/retrieve some kind of idealistic vision of Tokunoshima truth. Would that be more honest? The question for me is this: "how can my life be well-integrated, reconciled, but also well-lived?"

The problem is that I do not believe that an education system developed to serve the goals of capitalism can ever be modified to serve the goals of Indigenous peoples. From my perspective, a system that was established to serve and protect the interests of the ruling classes cannot now be tinkered with and become a system that serves and protects the interests of social justice. In fact, the world-dominant formal education system was built at the request of capitalists on the late 1800s ideology that workers needed to be literate (Musgrave, 1968, cited in Welch 1998). The dominant society's education system has bulldozed our houses, and built modern houses, and we cannot now 
effect change by redecorating them. Indeed, in an ideal world, the idea of education, the concepts of public schooling, must be broken down. The foundations must be smashed and the land they stand on reclaimed. Then, we stand together on the land, stop reminiscing, acknowledge that what stood here in the past cannot be reproduced, and make decisions about the ends we need to achieve, and the kinds of houses we will build together in accordance with local land/Nature. But this will not happen until there is dramatic intervention in the form of global warming, flooding cities and industries, devastating much of the world's population, and sending the surviving people back to the land or other similar human-initiated natural disaster. Until that time, I might lead, but no one will follow. It will take such a catastrophic event to change what has now become our ontology.

Within real life conditions, what is really happening and what people are doing when they encounter the dominant force/hegemony is assimilating into the dominant society. There is an insidious shift within each person's ontology and epistemology which I have observed even on my "remote" and isolated island over a very short period of time (Nakagawa, 2008). In fact, I did not even need to observe the changes in others; I should have known that I myself am also shifting and changing, without me even recognizing it. Perhaps because of the shifts and changes that I am experiencing in my life and education in Canada, perhaps because I have placed myself away from my own community, area, and even my nation, I am now capable of seeing the importance of my own language and culture within that nation, capable of viewing Japan as an aggressor nation to be resisted, rather than as an ideal and model to be emulated. I now need to learn to become accountable for those shifts and changes, and become prepared to act responsibly. I need to discover what is a Tokunoshima form of "warrior scholarship" (Alfred, 2004) for myself and for islanders because only isolating, nurturing and protecting our traditional ways will protect us from losing what we cannot recreate.

McLaren (1998) noted that the fundamental intention of many critical theorists and practitioners is to emancipate the oppressed from their dominators, "...to empower the powerless and transform existing social inequalities and injustices" (p. 160). The question for me is how and when the current education system shifted its foundation from the preparation of workers for a capitalist society, to the nurturing of young people who are able to think critically (Burbules \& Berk, 1999). I am not sure that it has shifted. Common criticisms of education today focus on how schools are becoming the tools of business, training workers for industrial efficiency (e.g., Apple, 1995) — but they always were. Does this suggest that critical thinkers do not look back and originate their thoughts in a historiographical/genealogical standpoint (Gale, 2001)? Or, does it mean 
that the education system has changed so that it now fosters critical thinking (Burbules \& Berk, 1999)? If the historical data about the origins of public schooling are correct, then the kinds of critical thinking reviewed by Burbules and Berk (1999) do not have a place to stand as theory. That is, such critical thinking theory is still within the IBK system and cannot go beyond/under/past it.

\section{Being is shaping knowing}

To further illustrate how criteria are set from the dominant culture's values rather than local/Indigenous values, I will use an example from health and longevity within my people. People on Tokunoshima and from the surrounding area called Amami, and as well as the greater area of Okinawa, they were and still are well-known for the longevity of the people (Nakamoto, 2006). Buettner (2005) remarked that on the islands of Okinawa, Japan, one of his teams of researchers examined a group of people that is among the longest living on Earth. However, Onishi (2004) has pointed out that the Okinawans' change in diet and lifestyle (i.e., American) is reducing their life expectancy and their health status. Furthermore, in the same article, Onishi (2004) quotes an Okinawan named Mr. Kamizato who, at "5-foot-5 ... had slimmed down to 168 pounds from 181 in the last three months. At his peak, five years ago, he had ballooned to 212 pounds" (p. 2):

"Don't get me wrong," he said, pausing on a treadmill. "I still think American food is the best in the world. Things have just changed from the viewpoint of health. It's bad for you, we know now. But it's the most delicious - by far. I still love it. If there was a burger here, right here, I'd eat it (p. 2).

Mr. Kamizato's statement strongly indicates that changing his ontology (how he lived) changed his epistemology (what he valued), and also changed his way of life from local/Indigenous ways to the ways of the dominant culture.

Mr. Kamizato has changed his definition of happiness (in this case, taste) from that of the local/Indigenous culture to that of the dominant culture. Greater consequences would result if the definition of happiness for the community was not merely the taste of fast food, but the whole way of life that comes with capitalism. For Mr. Kamizato and many other islanders, the consequences of mainstreaming can be seen directly in the state of their health. On the one hand, recognizing this phenomenon is simply finger pointing at the effects of globalization. Historically, Okinawa people had enough food to eat if 
they worked hard either at agriculture or fishing. However, Okinawans did not have enough food to create their own fast food obsessions. From this example, it can be assumed that Okinawans are now relying on outside providers for their food sources through the exchange of currency. While some may see this as the McDonaldization effect, it may be too simple to explain this away through the narratives of globalization. To do so may be using "globaloney" (Veseth, 2005), that is, a

...set of political, social, and economic arguments that draw upon certain vivid images, persuasive narratives, and memorable anecdotes or examples that are claimed to represent the causes or effects of globalization. (p. 20)

The ontological shift for the Okinawans which is represented by Mr. Kamizato may be globaloney, but it is also real and is now significantly affecting the way of life, epistemology, world view, value, and truth in the islands. The imprint of our people is changing. Despite the common assumption among critical thinkers and pedagogues that knowing will shape being (that is, that critically analyzing a situation can lead to changes in how we live), in fact, being shapes knowing (that is, how we live will change the way in which we think).

\section{Conclusion}

In this paper, I have suggested that current educational systems are based on information-based knowledge (IBK), which is replacing and/or annexing the wisdom-based knowledge (WBK) of Indigenous societies. I have noted that IBK is

pleasure-knowledge, what we could call brain candy for individuals, while wisdom-based knowledge can be viewed as consensus and truth seeking within a specific local land/Nature. I have argued that if WBK is the first imprint on children, then WBK will be their foundation, but if IBK is the first imprint on children, then that will be their foundation. I have suggested that every person in every society has learned WBK until the advent of schooling. In school, children are drilled intensively in IBK, and therefore they replace or repress WBK. Therefore, I have argued that schools are not the places to learn WBK. The knowledge we need to sustain and promote for the future is WBK.

Alfred (2004) notes that "there is enough knowledge, and enough analyses of the situation, but a desperate lack of action on what we have learned" (p. 96). Similarly, when I compare how I live as an Indigenous person with how I live as an Indigenous researcher/theorist, there is no comparison. If I am sitting in my office, wearing a T-shirt 
when it is minus 30 degrees outside, theorizing about how Indigenous people should act and live, rather than acting and living those experiences, then that is what our next generation will do as well. I do not think that there is anything wrong with IBK based education for dominant culture people. Their institutions will reinforce their knowledge, and their truth(s). On the other hand, I need to act rightly for my people. By acting/living rightly, I will rediscover my WBK.

Those of us who have higher education are automatically recognized by the dominant ideology. Those of us who hold higher degrees from such institutions need to change our own positions from information providers to "warriors of the truth" (Alfred, 2004, p. 95) against the hegemony of dominant cultures. It is clear that next generations will follow in the footsteps of the current leaders. In an information society, those of us who hold higher degrees are often perceived to be leaders of any society. It is important to recognize instead that I (we) as Ph.D.s and Masters' degree holders should not represent myself (our) as leaders of my (our) communities. Instead, scholars need to become servants to both their communities and to their community-selected leaders. At the same time, we must find ways to fight within the dominant societies to stall or even stop their encroaching forces, like IBK education. By becoming servants to their communities, I (or those who achieved higher education in IBK) will be able to show that I (we) believe that the enveloping knowledge system should be WBK rather than IBK by our own actions rather than by our talk. If we are to be leaders, we need to achieve the highest form of IBK that we can, and then walk away-not from the knowledge itself, but from the positions and the powers it represents.

Of course, the irony is that by representing these ideas in this text, I have had to invoke IBK. As soon as arguments are frozen, archived, in text, they become IBK rather than WBK which is embedded in action and negotiated/sustained through immediately-evaporating talk. But, that discussion is the subject of another paper (Nakagawa, 2007).

\section{References}

Alfred, T. (1999). Peace, power, righteousness: An Indigenous manifesto. Oxford, UK: Oxford University Press.

Alfred, T. (2004). Warrior scholarship: Seeing the university as the ground of contention. In D.A. Mihesuah \& A.C. Wilson (Eds.), Indigenizing the academy: Transforming scholarship and empowering communities (pp. 88-99). Omaha: University of Nebraska Press. 
Allen, P.G. (1989). Spider woman' granddaughters: Traditional tales and contemporary writing Writing by Native American Women. Boston, MA; Beacon Press. Anderson, H. (2003). As if gender mattered: Feminism and change in higher education. The Journal of Higher Education, 74(3), 321-336.

Apple, M. (1995). Education and power, $2^{\text {nd }}$ ed. New York: Routledge.

Bhabha, H. (1994). The location of culture. New York: Routledge.

Bloom B.S. (1964). Stability and change in human characteristics. New York: John Wiley \& Sons, Inc.

Buettner, D. (2005, November). Residents of Okinawa, Sardinia, and Loma Linda, California, live longer, healthier lives than just about anyone else on Earth. What do they know that the rest of us don't? National Geographic, Washington, D.C.: National Geographic Society.

http://www7.nationalgeographic.com.login.ezproxy.library.ualberta.ca/ngm/0511/feature 1/index.html Accessed on March 25, 2007.

Burbules, N. \& Berk, R. (1999). Critical thinking and critical pedagogy. In T. Popkewitz \& L. Fendler (Eds.), Critical Theories in Education (pp. 45-66). New York: Routledge.

Canagarajah, Suresh. (2002). Reconstructing local knowledge. Journal of Language, Identity, and Education, 1, 243-259.

Dei, G.J.S. (1996). Anti-Racism Education. Halifax, Canada: Fernwood.

Ermine, W. (2006). The space between two knowledge systems. Paper presented at Positioning Ourselves: Indigenous knowledges conference, Department of Educational Policy Studies, University of Alberta, March 8, 2006.

Esteva, G. (1996). Hosting the otherness of the other: The case of the green revolution. In F. Apffel-Marglin \& S. A. Marglin (Eds.), Decolonizing knowledge from development to dialogue. Clarendon Press, Oxford, England.

Freire, P. (1970). Pedagogy of the oppressed. New York, USA: Continuum.

Gadamer, H.G. (2000). The beginning of philosophy. R. Coltman (Trans.). New York: Continuum.

Gale, T. (2001). Critical policy sociology: Historiography, archeology, and genealogy as methods of policy analysis. Journal of Educational Policy, 16, 379-393.

Gottfried, B.M., Andrews, K., \& Haug, M. (1985). Breeding robins and nest predators: Effict of predator type and defense strategy on initial vocalization patterns. Wilson Bulletin, 97, 183-190.

Grande, S. (2004). Red pedagogy: Native American social and political thought. Oxford, UK: Rowan \& Littlefield. 
Hozumi, S. (1995). Nantou zatsuroku shu [Southern Islands Journal collection]. Ooshima-gun, Japan: Fujita Insatsu.

Kouritzin, S. \& Nakagawa, S. (forthcoming). What is postcolonial pedagogy in TESL/TEFL? Paper to be presented January 2009 at the Hawaii International Conference on Education, Honolulu, Hawaii.

Lafrance, J. \& Bastien, B. (2007). Here be dragons! Reconciling Indigenous and Western knowledge to improve Aboriginal child welfare. First Nations Child and Family Review, 3(1), 105-126.

Lenneberg, E.H. (1967). Biological foundations of language. New York, USA. John Wiley \& Sons, Inc.

Lenneberg, E.H. (1971). Language knowledge: Formal constants of cognitive achievement. Journal of Psycholinguistic Research, 1, 1-29.

Maher, J.C. (2001). Preface. In M.G. Noguchi \& S. Fotos (Eds.) Studies in Japanese bilingualism. Clevedon, UK: Multilingual Matters.

Marx, K. (2005). G. Nakayama, K. Nishima, M. Tokunaga, S. Muraoka (Trans.). Marx Collection I: Democritos no Shizen tetsu gakku to epicross no shizen tetsu gakku no sai: Hegel hou tetsu gakku hihan josetsu: Yudaiajin mondai ni yosete: Kaizai gakku/Tetsu gakku soukou. [Differences between Democritos and Epicritos Philosophy: Critique of Hegel: The Jewish problem: Notes on Economics/Philosophy. Tokyo: Chikuma Shoubou.

Marx, K. (1906). Capital: A critique of political economy. Toronto, Canada: Random House.

McLaren, P. (1998). Life in school: An introduction to critical pedagogy in the foundations of education. New York: Longman.

Musgrave, P.W. (1968). Society and education in England since 1800. London, UK: Methuen and Co Ltd.

Nadasdy, P. (2006). The case of the missing sheep: Time, space, and the politics of "trust" in co-management practice. In C.R. Menzies (Ed.), Traditional ecological knowledge and natural resource management (pp. 127-151). Lincoln, NE: University of Nebraska Press.

Nakamoto, K. (2006). Lessons learned from Okinawa longevity. Japanese Medical Society of America Health Journal, 1, 2-4.

http://jmsa.org/jmsa_hj/JMSA_HJ_1-4.pdf Accessed on March 25, 2007.

Nakagawa, S. (2008, May 3). What is the "gold standard" for revitalizing languages? Paper presented at the $15^{\text {th }}$ Annual Stabilizing Indigenous Languages Conference: Language is life: Strategies for Language revitalization, Northern Arizona 
University, Flaggstaff, Arizona.

Nakagawa, S. (2007). Accord or Discord: Returning to oral traditions? Canadian Journal of Native Studies, 27, 451-478.

Nakata, M. (2002). Indigenous knowledge and the cultural interface; Underlying issues at the intersection of knowledge and information systems, IFLA Journal, 28(5/6), 281-291.

Ong, W.J. (1977). Interfaces of the word: Studies in the evolution of consciousness and culture. Ithaca, NY: Cornell University Press.

Onishi, N. (2004). Urasoe Journal; On U.S. fast food, more Okinawans grow super-sized. The New York Times. March 30, 2004.

http://www.nytimes.com/2004/03/30/international/asia/30FAT.html?ex=1395982800\&en $=88 \mathrm{~d} 4 \mathrm{e} 6 \mathrm{~d} 7493 \mathrm{da} 93 \mathrm{c} \& \mathrm{ei}=5007 \&$ partner$=$ USERLAND Accessed on March 25, 2007.

Rooney, D. (2005). Knowledge, economy, technology and society: The politics of discourse. Telematics and Informatics, 22, 405-422.

Rosenhan, D. \& White, G.M. (1967). Observation and rehearsal as determinants of prosocial behavior. Journal of personality and social psychology, 5, 424-431.

Rosenhan, D., Frederick, F. \& Burrowes, A. (1968). Preaching and practicing: effects of channel discrepancy on norm internalization. Child Development, 39, 291-301.

Sinha, C. (2004). The evolution of language: From signals to symbols to system. In D.K. Oller \& U. Griebel (Eds.), Evolution of communication systems - A comparative approach (pp. 217-235). London, England: The MIT Press.

Slater, P.J.B., Ince, S.A., \& Colgan, P.W. (1980). Chaffinch song types: Their frequencies in the population and distribution between repertoires of different individuals. Behavior, 75, 207-218.

Smith, L.T. (1999). Decolonizing methodologies: Research and indigenous peoples. London: Zed Books.

Snowdon, C.T. (2004). Social process and evolution of complex communication. In D.K. Oller \& U. Griebel (Eds.), Evolution of communication systems - A comparative approach (pp. 131-150). London, England: The MIT Press.

Stewart-Harawira, M. (2005). The new imperial order: Indigenous responses to globalization. London: Zed Books.

Stern, N.H. (2006). Stern review: the economics of climate change. Pre-publication ed., London, England. HM Treasury.

Tai, E. (2003). Rethinking culture, national culture, and Japanese culture. Japanese Language and Literature, 37, 1-26. 
Veseth, M. (2005). Globaloney: unraveling the myths of globalization. Lanham, USA: Rowman \& Littlefield.

wa Thiong'o, N. (1986). Decolonizing the mind: The politics of language in African literature. London: James Curry.

Welch, A.R. (1998). The cult of efficiency in education: comparative reflections on the reality and the rhetoric. Comparative Education, 34, 157-175.

Wong Fillmore, L. (1991). When learning a second language means losing the first. Early Childhood Research Quarterly, 6, 323-346. 